\title{
Use of Extracorporeal Membrane Oxygenation in a Fulminant Course of Amniotic Fluid Embolism Syndrome Immediately after Cesarean Delivery
}

\author{
Jae Ha Lee, M.D. ${ }^{1}$, Hang Jea Jang, M.D. ${ }^{2}$, Jin Han Park, M.D. ${ }^{2}$, Yong Kyun Kim, M.D. ${ }^{2}$, Ho Ki Min, M.D. ${ }^{2}$, \\ Sun Young Kim, M.D. ${ }^{2}$, and Hyun-kuk Kim, M.D. ${ }^{2}$ \\ ${ }^{1}$ Department of Internal Medicine, Seoul St. Mary's Hospital, The Catholic University of Korea College of Medicine, Seoul; '2Department of Internal Medicine, Haeundae Paik Hospital, \\ Inje University College of Medicine, Busan, Korea
}

Amniotic fluid embolism is rare but is one of the most catastrophic complications in the peripartum period. This syndrome is caused by a maternal anaphylactic reaction to the introduction of fetal material into the pulmonary circulation. When amniotic fluid embolism is suspected, the immediate application of extracorporeal mechanical circulatory support such as veno-arterial extracorporeal membrane oxygenation (ECMO) or cardiopulmonary bypass should be considered. Without the application of extracorporeal mechanical circulatory support, medical supportive care might not be sufficient to maintain cardiopulmonary stabilization in severe cases of amniotic fluid embolism. In this report, we present the case of a 36-year-old pregnant woman who developed an amniotic fluid embolism immediately after a cesarean section. Her catastrophic event started with the sudden onset of severe hypoxia, followed by circulatory collapse within 8 minutes. The veno-arterial mode of extracorporeal membrane oxygenation was initiated immediately. She was successfully resuscitated but with impaired cognitive function. Thus, urgent ECMO should be considered when amniotic fluid embolism syndrome is suspected in patients presenting acute cardiopulmonary collapse.

Key Words: amniotic fluid embolism; anaphylaxis; extracorporeal membrane oxygenation.

Amniotic fluid embolism is rare but one of the leading causes of maternal mortality. In a previous study of women who experienced amniotic fluid embolism, $[1] 70 \%$ of the cases occurred during labor, $11 \%$ occurred after vaginal delivery, and $19 \%$ occurred during cesarean section after delivery of the infant. The initial sign of amniotic fluid embolism is hypoxia, which is associated with acute right ventricular failure. This right ventricular failure is not the result of pulmonary vascular obstruction by embolic material, but of pulmonary vasoconstriction by amniotic fluid contents. Amniotic fluid includes many endogenous mediators and the entry of tiny amounts of these endogenous mediators into the systemic maternal circulation could trigger an anaphylactic reaction.[2] It has been proposed that amniotic fluid embolism is more of an immunologic than an embolic phenomenon.

Received on March 17, 2016 Revised on May 17, 2016 Accepted on May 18, 2016

Correspondence to: Hang Jea Jang, Department of Internal Medicine, Haeundae Paik Hospital, Inje University College of Medicine, 875 Haeun-daero, Haeundaegu, Busan 48108, Korea

Tel: +82-51-797-3009, Fax: +82-51-797-0100

E-mail: okabang021@gmail.com

*No potential conflict of interest relevant to this article was reported.
The initial hypoxia in amniotic fluid embolism is followed by rapidly progression to the catastrophic event of circulatory collapse; thus, the veno-arterial mode of extracorporeal membrane oxygenation (ECMO) is most likely the only option to save the life of the patient. Extracorporeal mechanical circulatory support is required for successful 
cardiopulmonary resuscitation in most cases of amniotic fluid embolism.[3,4]

\section{Case Report}

A 36-year-old primigravida woman with a twin pregnancy by in vitro fertilization was admitted to the labor and delivery service at our hospital. She had suffered from gestational hypertension and diabetes mellitus during the pregnancy. Laboratory findings, including complete blood count (white blood cell 6,410 cells $/ \mathrm{mm}^{3}$, hematocrit $32.7 \%$, platelets $247 \times 10^{3} / \mathrm{mm}^{3}$ ), liver function test, electrolytes (blood urea nitrogen [BUN] $5.0 \mathrm{mg} /$ $\mathrm{dL}$, creatinine $0.56 \mathrm{mg} / \mathrm{dL}$, sodium $140 \mathrm{mEq} / \mathrm{L}$, chloride $110 \mathrm{mEq} / \mathrm{L}$, potassium $3.8 \mathrm{mEq} / \mathrm{L}$, glucose $90 \mathrm{mg} / \mathrm{dL}$ ), and coagulation profile (prothrombin time 10.9 seconds, international normalized ratio [INR] 1.01, activated prothrombin time 24.9 seconds) were within normal limits. Chest radiography and electrocardiography were not remarkable. Because of an uncontrollable progression of labor, the patient underwent an emergency low-transverse cesarean section at 30 weeks and 5 days of gestation under general anesthesia. She delivered twin babies without any adverse events. Upon completion of surgery, she was extubated and was awake and alert. Blood pressure was $140 / 110 \mathrm{mmHg}$ and heart rate 110 beats/minute. During the surgery, $2800 \mathrm{~mL}$ of crystalloids and $600 \mathrm{~mL}$ of colloid were administered. Intraoperative blood loss was $600 \mathrm{~mL}$, and urine output was $500 \mathrm{~mL}$. Shortly after extubation, she suddenly became breathless and cyanotic. Oxygen saturation according to pulse oximetry was $75 \%$ and decreased to $40 \%$. She was reintubated promptly and placed on mechanical ventilation with $100 \%$ oxygen. $\mathrm{SpO}_{2}$ increased to $90 \%$. The end-tidal $\mathrm{PCO}_{2}$ was $15 \mathrm{mmHg}$ initially and then decreased to zero. She also developed hypotension and bradycardia, and her heart stopped beating. Only 7 or 8 minutes elapsed between the onset of dyspnea and cardiac arrest, despite the effort to resuscitate her with an immediate intervention. Cardiopulmonary resuscitation was started, along with infu- sion of vasopressors and inotropic agents. Veno-arterial ECMO, which is essentially a heart-lung machine without a reservoir, providing both respiratory and circulatory support, was applied immediately via the femoral vein and artery after 3,000 units of heparin were administered. After vessel puncture and guide-wire placement, venous access with a 28 -French cannula was directed through the right femoral vein to the right atrium under transthoracic echocardiographic guidance, and arterial access with a 16-French cannula was introduced into the left femoral artery. A CAPIOX ${ }^{\circledast}$ EBS circuit (Terumo Inc., Tokyo, Japan) and CAPIOX ${ }^{\circledR}$ SP pump console SP-101 (Terumo Inc., Tokyo, Japan) were used. The initial setting of the ECMO included a blood flow of $6.0 \mathrm{~L} /$ minute and $\mathrm{FiO}_{2}$ of 0.75 . With the initiation of ECMO, 20 minutes after cardiopulmonary arrest, the patient's vital signs became stable (blood pressure was 149/106 mmHg, heart rate 115 beats/minute, and $\mathrm{SpO}_{2} 100 \%$ ), and most of the vasoactive medications were tapered gradually. The patient was sent for chest computed tomography (CT) angiography to rule out other major problems than amniotic fluid embolism before being transferred to the intensive care unit. Chest CT angiography revealed no pulmonary embolism, but intense parenchymal opacification in the bilateral-dependent lung and nondependent ground-glass opacification were apparent (Fig. 1). Transthoracic echocardiography revealed left ventricular global hypokinesia with severe left ventricular dysfunction (Fig. 2). There was a significant amount of vaginal bleeding; hematocrit was $26.9 \%$, and platelet count was $72,000 / \mathrm{mm}^{3}$. Prothrombin time was 16.9 seconds, INR 1.61, and activated thromboplastin time 63.0 seconds.

On the first day in the intensive care unit (ICU), the patient was hemodynamically stable with an ECMO blood flow rate of $4.6 \mathrm{~L} /$ minute. Urine output had been greater than $1 \mathrm{~mL} / \mathrm{kg}$ of body weight/hour. The lactate level was less than $4 \mathrm{mEq} / \mathrm{L}$. Arterial blood gases while on an $\mathrm{FiO}_{2}$ of 0.6 with ECMO indicated that $\mathrm{pH}$ was 7.43, $\mathrm{PCO}_{2} 29$ $\mathrm{mmHg}, \mathrm{PO}_{2} 166 \mathrm{mmHg}$, and $\mathrm{HCO}_{3}^{-} 19.2 \mathrm{mEq} / \mathrm{L}$. Fibrin degradation product was $58.3 \mathrm{mcg} / \mathrm{mL}$, D-dimer 24.8 $\mathrm{mcg} / \mathrm{L}$, and fibrinogen $194 \mathrm{mg} / \mathrm{dL}$. For the evaluation of 

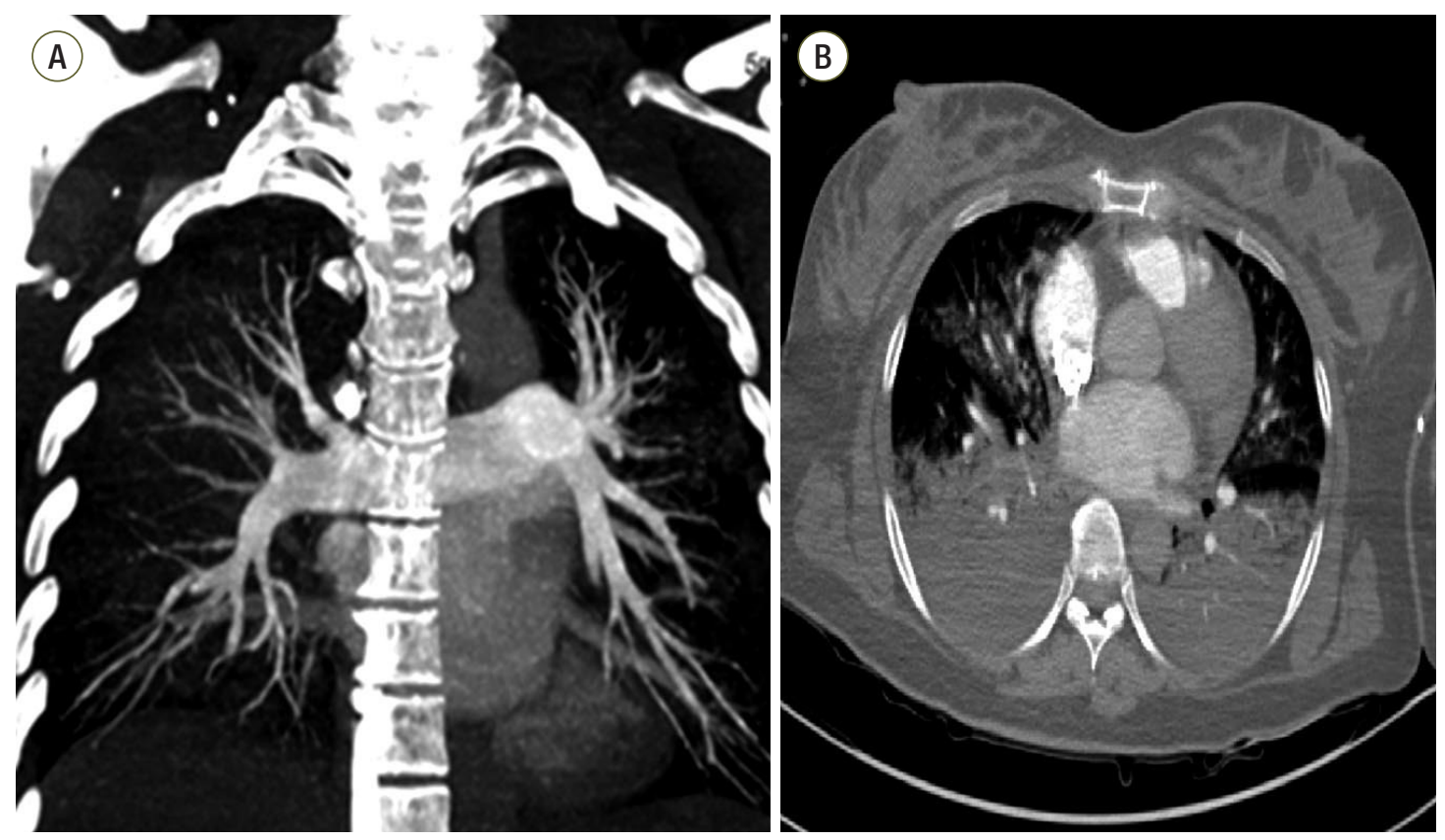

Fig. 1. Computed tomography (CT) scans from a 36-year-old female who survived acute respiratory distress syndrome. (a) CT pulmonary angiography with coronal maximum intensity projection reconstruction reveals no filling defect. (b) Axial CT scan with lung algorithm displays typical areas of intense parenchymal opacification in the dependent lung and nondependent ground-glass opacification.
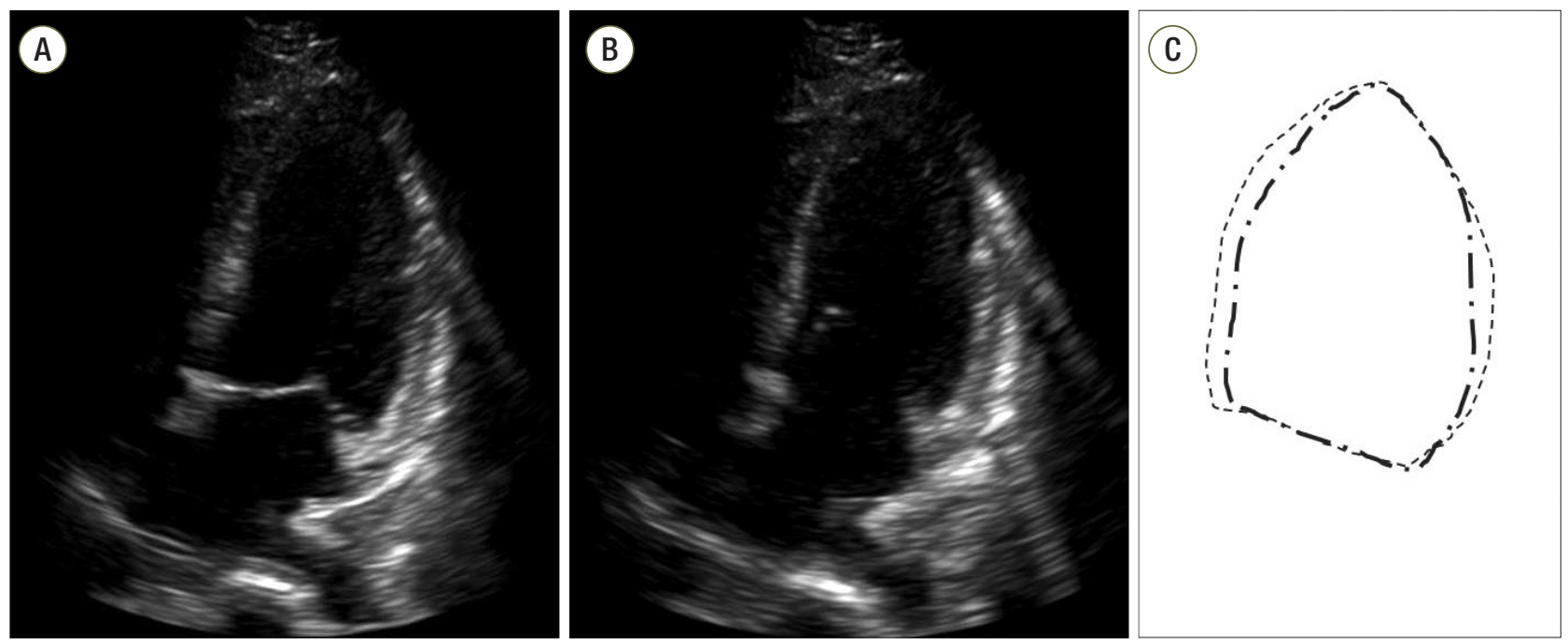

Fig. 2. Echocardiograms (A, B) and schematic representation of the left ventricular (LV) echocardial borders (C) during diastole and systole. Transthoracic 4-chamber view at admission demonstrates apical and midventricular dilatation of the LV, accompanied by severe global hypokinesia.

hemodynamic functions, including the degree of pulmonary vasoconstriction and left ventricular filling pressure, a pulmonary artery catheter was introduced through the right internal jugular vein. Initially, mean pulmonary arterial pressure and pulmonary capillary wedge pressure were
$40 \mathrm{mmHg}$ and $18 \mathrm{mmHg}$, respectively, and these slowly normalized over time. A blood sample from the pulmonary artery catheter with the balloon inflated was sent to pathology for cytological analysis. The result a few days later revealed the presence of degenerated squamous cells, 


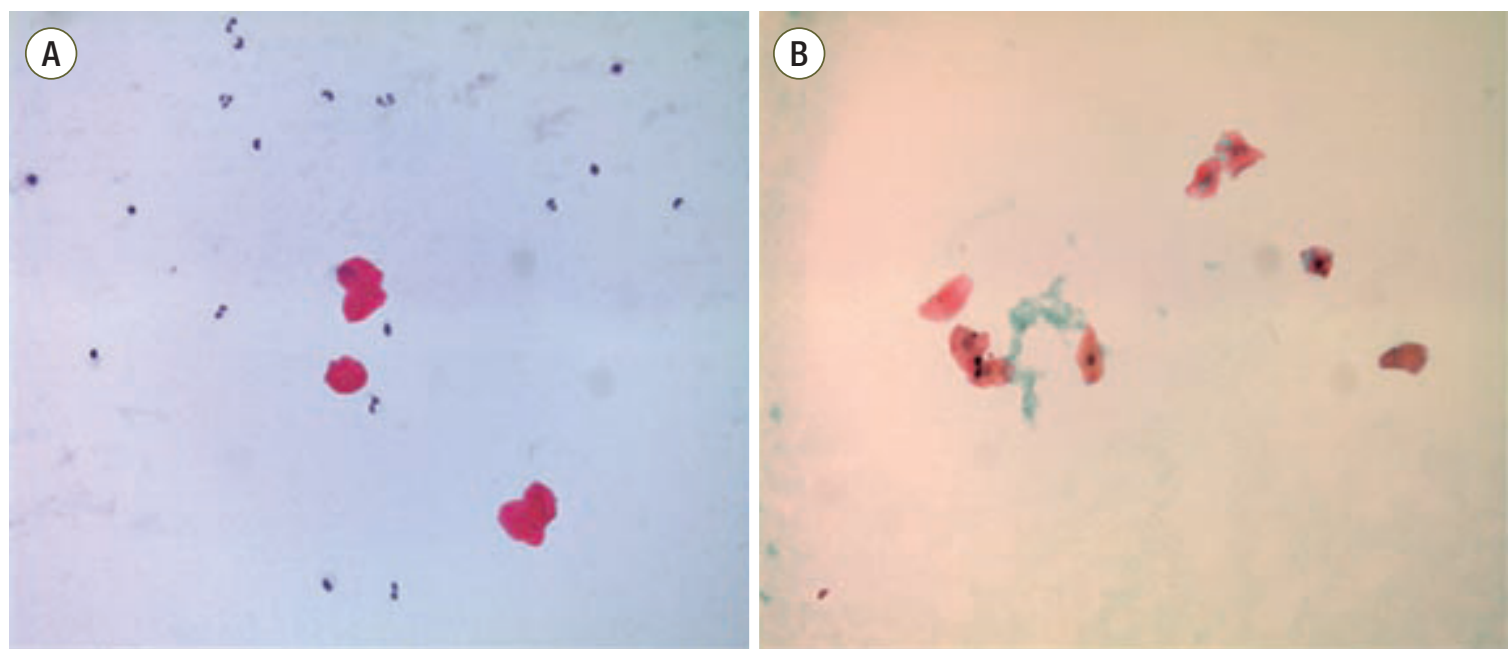

Fig. 3. Pathology of a central venous blood sample reveals degenerative squamous epithelium (A: Hematoxylin and eosin stain, B: Papanicolaou stain).
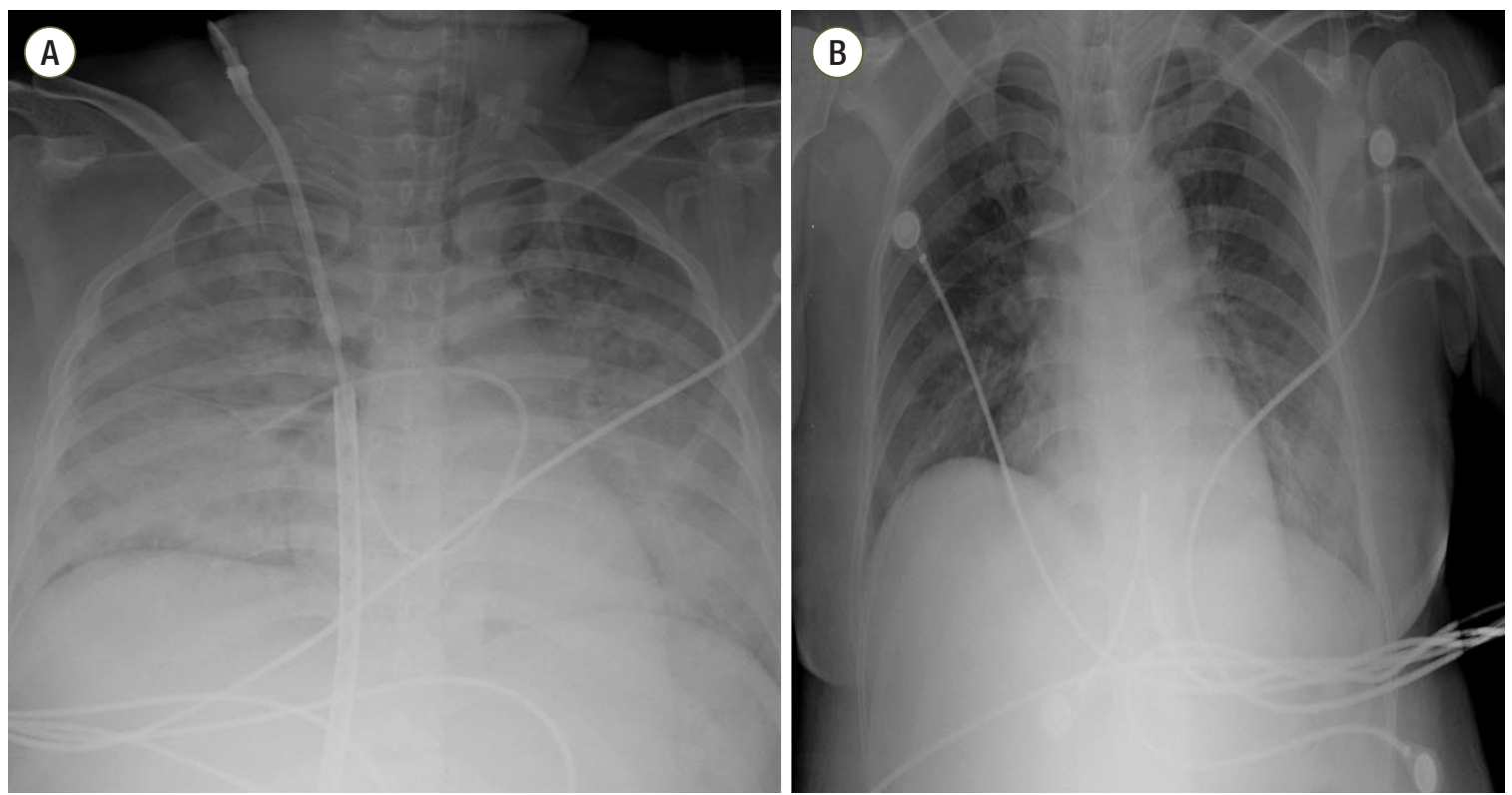

Fig. 4. Chest radiograph from a 36-year-old female who survived acute respiratory distress syndrome. (A) Initial chest radiograph displays typical areas of diffuse consolidation in both lungs. The patient required extracorporeal membrane oxygenation (ECM0) due to uncorrected desaturation. (B) After 1 week, the ECMO catheter was removed. The chest radiograph displays the reduced extent of consolidation and improved aeration in both lungs.

indicating amniotic fluid embolism (Fig. 3). On the patient's second day in the ICU, follow-up echocardiography revealed nearly normalized left ventricular systolic function. Analysis of arterial blood gases while she was on the mechanical ventilator with a positive end-expiratory pressure of $5 \mathrm{~cm} \mathrm{H}_{2} \mathrm{O}$ and an $\mathrm{FiO}_{2}$ of 0.4 indicated that $\mathrm{pH}$ was $7.45, \mathrm{PCO}_{2} 33 \mathrm{mmHg}, \mathrm{PO}_{2} 143 \mathrm{mmHg}$, and
$\mathrm{HCO}_{3}{ }^{-} 22.9 \mathrm{mEq} / \mathrm{L}$. Hematocrit was $28.9 \%$, and platelet count $140 \times 10^{3} / \mathrm{mm}^{3}$. BUN was $27.0 \mathrm{mg} / \mathrm{dL}$, and creatinine $0.88 \mathrm{mg} / \mathrm{dL}$. On the third day in the ICU, the patient was weaned off ECMO, and a chest radiograph revealed a reduced extent of consolidation and improved aeration in both lungs (Fig. 4). On the patient's seventh day in the ICU, a tracheostomy was performed in anticipation 
of prolonged ventilatory support and airway problems because of an altered mental status, which is one of the cardinal findings of amniotic fluid embolism. Although the patient was awake, she was unable to obey verbal commands. On the 11th day in the ICU, she was weaned off the ventilator and transferred to the general ward. On the 40th hospital day, she was discharged with impaired cognitive function to a nursing home. And premature twin babies who were transferred to neonatal ICU for care of incubator were discharged safely with mother in healthy state.

\section{Discussion}

The specific clinical menifestations of amniotic fluid embolism are respiratory distress, cardiovascular collapse, encephalopathy and consumptive coagulopathy. [5] Respiratory distress is sudden in onset, abruptly deteriorates and severe hypoxia is accompanied. The early hypoxia is associated with a serious mismatch of ventilation and perfusion caused by severe right heart failure. [3] Cardiogenic pulmonary edema caused by severe left ventricular dysfunction can have an affect on hypoxia. Cardiovascular collapse is another features of amniotic fluid embolism and occurs in severe cases,[5] requiring extracorporeal mechanical circulatory support such as veno-arterial ECMO for successful resuscitation.[3,6] In the patient of the present report, the initial catastrophic event was short. Within only 7 or 8 minutes of the onset of dyspnea, the patient's heart stopped beating, despite ventilatory support. Thus, hypoxia was not the only cause of cardiac arrest. Cardiovascular collapse results from diastolic dysfunction of the left ventricle related with increased right heart pressure, which is caused by pulmonary vasoconstriction, and interventricular septal shifting. Left ventricular dysfunction will worsen by hypoxia and ischemia. As such, the veno-arterial mode of ECMO was the only option to save the life of the patient. Without extracorporeal mechanical circulatory support, cardiopulmonary resuscitation for amniotic fluid embo- lism has not been successful in most cases.[3,4]

The absence of pulmonary embolism as determined by chest $\mathrm{CT}$ angiography in the patient in the present report does not rule out amniotic fluid embolism. Amniotic fluid includes many endogenous mediators, such as platelet activating factor, phospholipase A2, endothelin, thromboplastin and prostaglandin, and entry of tiny amounts of these endogenous mediators into the systemic maternal circulation can trigger an anaphylactic reaction. [2] It has been proposed that amniotic fluid embolism is more of an immunologic than an embolic phenomenon. [1] This would explain why fetal cells have not always been found in women who have experienced amniotic fluid embolism. Right ventricular failure is not the result of pulmonary vascular obstruction by embolic material, but of pulmonary vasoconstriction by amniotic fluid contents.

DIC is a prominent manifestations of amniotic fluid embolism, present in more than $83 \%$ of such patients.[7] The onset of DIC can occur as quickly as 10-30 minutes from start of signs or may occur with a delay by as many as 4 hours. This consumptive coagulopathy may be associated with fibrinolysis due to elevated level of plasminogen activation inhibitor 1 in amniotic fluid. [8] In the patient in the present report, the fibrinogen level was still low, and fibrin degradation product and D-dimer levels were elevated the following morning. The platelet count about one hour after the initiation of ECMO was only 72 $\times 10^{3} / \mathrm{mm}^{3}$, reduced from the preoperative level of 247 $\times 10^{3} / \mathrm{mm}^{3}$. These laboratory values strongly support the presence of DIC.

Encephalopathy is a common neurological symptoms in patients with amniotic fluid embolism and is provoked by hypoxia and decreased oxygen delivery to the brain. [3] However, brain CT was negative for lesions, and only magnetic resonance imaging (MRI) revealed a diffuse cortical injury in the patient of the present report. In cerebral fat embolism syndrome, lesions are not apparent in brain CT, but MRI shows a "star field" appearance,[9] indicating multiple foci of restricted diffusion. It is possible that tiny masses fat tissue that pass through pulmo- 
nary capillaries cause brain lesions which are not detectable by CT but are detectable by MRI. If this is the case, the same may be possible in amniotic fluid embolism. In some patients with amniotic fluid embolism, encephalopathy may be due to embolization of amniotic debris rather than hypoxia or ischemia of the brain.

In conclusion, ECMO should be considered as an initial option to save the life of a patient with amniotic fluid embolism who develops cardiopulmonary collapse.

\section{ORCID}

$\begin{array}{ll}\text { Jae Ha Lee } & \text { http://orcid.org/0000-0003-0932-2826 } \\ \text { Hang Jea Jang } & \text { http://orcid.org/0000-0001-7733-4365 } \\ \text { Yong Kyun Kim } & \text { http://orcid.org/0000-0002-7935-6952 }\end{array}$

\section{References}

1) Clark SL, Hankins GD, Dudley DA, Dildy GA, Porter TF: Amniotic fluid mbolism: ional registry. Am J Obstet Gynecol 1995; 172: 1158-67.

2) Walsh SW, Wang Y, Jesse R: Peroxide induces vasoconstriction in the human placenta by stimulating thromboxane. Am J Obstet Gynecol 1993; 169:
1007-12.

3) Ecker JL, Solt K, Fitzsimons MG, MacGillivray TE: Case 40-2012: a 43-year-old woman with cardiorespiratory arrest after a cesarean section. $\mathrm{N}$ Engl J Med 2012; 367: 2528-36.

4) Price TM, Baker VV, Cefalo RC: Amniotic fluid embolism. Three case reports with a review of the literature. Obstet Gynecol Surv 1985; 40: 462-5.

5) Moore J, Baldisseri MR. Amniotic fluid embolism. Crit Care Med 2005; 33: S279-85.

6) Stanten RD, Iverson LI, Daugharty TM, Lovett SM, Terry C, Blumenstock E: Amniotic fluid embolism causing catastrophic pulmonary vasoconstriction: diagnosis by transesophageal echocardiogram and treatment by cardiopulmonary bypass. Obstet Gynecol 2003; 102: 496-8.

7) Gist RS, Stafford IP, Leibowitz AB, Beilin Y: Amniotic fluid embolism. Anesth Analg 2009; 108: 1599602 .

8) Estellés A, Gilabert J, Andrés C, España F, Aznar J: Plasminogen activator inhibitors type 1 and type 2 and plasminogen activators in amniotic fluid during pregnancy. Thromb Haemost 1990; 64: 281-5.

9) Stoeger A, Daniaux M, Felber S, Stockhammer G, Aichner F, zur Nedden D: MRI findings in cerebral fat embolism. Eur Radiol 1998; 8: 1590-3. 